\title{
Qualitative and quantitative ultrasound assessment of gastric content
}

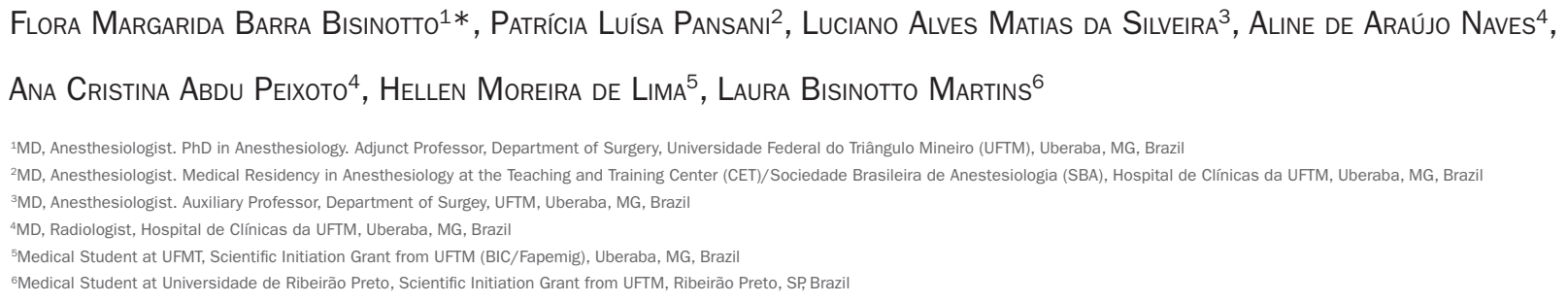

Study conducted by the Anesthesiology

Division at Hospital de Clínicas da Universidade Federal do Triângulo Mineiro (UFTM), Uberaba, MG, Brazi

Article received: 5/24/2016 Accepted for publication: 9/3/2016

*Correspondence: Address: Avenida Frei Paulino, 30 Uberaba, MG - Brazil

Postal code: $38025-180$ flora@mednet.com.b

Funding: Fundação de Amparo à Pesquisa de Minas Gerais (Fapemig) and Fundação de Ensino e Pesquisa de Uberaba (Funepu)

http://dx.doi.org/10.1590/1806-9282.63.02.134

\section{SUMmARY}

Objective: Pulmonary aspiration of the gastric contents is one of the most feared complications in anesthesia. Its prevention depends on preoperative fasting as well as identification of risky patients. A reliable diagnostic tool to assess gastric volume is currently lacking. The aim of this study performed on volunteers was to evaluate the feasibility of ultrasonography to identify qualitative and quantitative gastric content.

Method: A standardized gastric scanning protocol was applied on 67 healthy volunteers to assess the gastric antrum in four different situations: fasting, after ingesting clear fluid, milk and a solid meal. A qualitative and quantitative assessment of the gastric content in the antrum was performed by a blinded sonographer. The antrum was considered either as empty, or containing clear or thick fluid, or solids. Total gastric volume was predicted based on a cross-sectional area of the antrum. A p-value less than 0.05 was considered statistically significant.

Results: For each type of gastric content, the sonographic characteristics of the antrum and its content were described and illustrated. Sonographic qualitative assessment allowed to distinguish between an empty stomach and one with different kinds of meal. The predicted gastric volume was significantly larger after the consumption of any food source compared to fasting.

Conclusion: Bedside sonography can determine the nature of gastric content. It is also possible to estimate the difference between an empty gastric antrum and one that has some food in it. Such information may be useful to estimate the risk of aspiration, particularly in situations when prandial status is unknown or uncertain.

Keywords: gastric content, antral area, pulmonary aspiration, preoperative fasting, ultrasonography.

\section{INTRODUCTION}

Since Mendelson's description of gastric aspiration syndrome $^{1}$ in anesthetized parturient women in 1946, gastric content has become a constant concern among anesthesiologists, leading to the development of preoperative fasting guidelines. ${ }^{2,3}$ However, certain clinical conditions may predispose elective patients to present significant gastric content at the time of induction of anesthesia, even if the fasting time is appropriate. ${ }^{4,5}$ This problem is even greater when dealing with emergency surgeries. In this circumstance, gastrointestinal motility may be influenced by stress, the presence of pain and anxiety and the use of opioids, making it difficult to predict the gastric condition. Patients who have a "full stomach" are at risk of aspiration during sedation or general anesthesia due to reduction of the tonus of the lower esophageal sphincter and also protective airway reflexes. ${ }^{6,7}$ Certain factors have been associated with the severity of the evolution of patients suffering from pulmonary aspiration, including the volume, nature and the $\mathrm{pH}$ of the aspirated material. ${ }^{8-11}$ 
The preoperative assessment of the risk of pulmonary aspiration is essentially based on the patient's history, and clinical management typically follows the fasting recommendations of the current guidelines. ${ }^{2,3}$

Unfortunately, a final assessment of the nature and volume of the gastric content at bedside at any time is not easy, thus being inaccessible for anesthesiologists. Scintigraphy has been considered the gold standard for this assessment for many years. ${ }^{12,13}$ However, due to the cost, radiation exposure and the need for specific equipment, this technique has only been useful for research proposals. Gastric ultrasonography (USG) is the first non-invasive imaging examination that has been validated for this purpose, because it can provide information about the nature and volume of the gastric content at bedside. ${ }^{14-17}$ These facts have contributed to its use as a replacement technique, given that it is inexpensive and can be performed at bedside. USG versatility has enabled its use during the perioperative period for the assessment of the gastric content, a parameter of great importance especially in emergency situations, with the objective of providing more rational management and reducing the risk of aspiration.

Recent studies have shown sufficient evidence of its accuracy and reproducibility. ${ }^{14-17}$ Obviously, ultrasound examination does not provide a complete assessment of gastric function and status (e.g. pH), but it can provide important and useful information such as the volume and nature of the content (clear liquid, solid or none). ${ }^{14-19}$

Considering that USG is an examination rarely used for this purpose in our country, the objectives of this study were: 1 ) to describe the appearance of the stomach while empty and after ingestion of fixed volumes of different types of food; 2) to describe the interpretation of the radiological image undertaken by the examiner in relation to the type of food ingested; and 3) to evaluate the usefulness of the gastric USG in quantifying the gastric content following the ingestion of different foods and thereby use it as a tool for assessing the risk of gastric aspiration.

\section{Method}

After approval by the Research Ethics Committee (CEP) of the Federal University of the Triângulo Mineiro (UFTM) under number 1.448.546 and obtaining the informed consent of the participants, this cross-sectional and prospective study was conducted on 30 healthy volunteers. The inclusion criteria were: being aged between 20 and 60 years, physical status classification according to the American Society of Anesthesiologists (ASA) I or II, body mass index (BMI) of less than $30 \mathrm{~kg} / \mathrm{m}^{2}$, and the ability to understand the study protocol and informed consent. The exclusion criteria were considered as any condition that could interfere with the gastric emptying time, such as pregnancy, diabetes, or the presence of diseases of the gastrointestinal tract.

The volunteers were told to undergo a minimum nighttime fasting period of 8 hours, after which they would be examined randomly in several different situations, designated as the following groups: a) fasting (fasting group); b) 5 minutes after ingestion of $250 \mathrm{~mL}$ of clear fluid (isotonic solution) (isotonic group); c) 10 minutes after ingestion of $250 \mathrm{~mL}$ of non-clear liquid (milk group) (group L); or d) 10 minutes after ingestion of a solid meal (ham and cheese sandwich) (sandwich group). We established the volume of $250 \mathrm{~mL}$ of isotonic liquid and milk because this amount is greater than the upper limit of gastric volume of normal baseline fasting. ${ }^{20}$

Ultrasound assessment of the gastric content was conducted by an experienced professional at the Radiology Service of UFTM who was unaware of the quality or quantity of the ingested material. The tests were carried out using a technique described beforehand, ${ }^{14,15}$ using a convex probe $(2-5 \mathrm{MHz})$. The volunteers were examined in supine position, followed by right lateral decubitus position (RLDP). The transducer was placed on the sagittal plane in the epigastric region and the antrum and the gastric body were then scanned by moving the transducer from right to left, with the purpose of obtaining a general qualitative view of the cavity and the gastric content. A better view of the antrum is obtained on the parasagittal plane just to the right of the midline, with the left lobe of the liver anteriorly and the pancreas posteriorly as a reference point. The inferior vena cava is situated behind the pancreas. The gastric antral wall is characterized by multiple layers, and its visibility was assessed in a binary way (visible or not) in both positions, supine and RLDP. At visualization of the antrum, the stomach was considered empty if the anterior and posterior walls appeared juxtaposed. The antrum was regarded as containing liquid if it showed distended walls as well as endocavity with hypoechoic or anechoic content..$^{15,20,21}$ The images obtained after intake of milk and solid foods differ, depending on the time between ingestion and the ultrasound examination. The presence of milk, as well as thick fluids, increases the echogenicity. ${ }^{20}$ After a solid meal there is a substantial amount of air mixed with the bolus created by the processes of chewing and swallowing. The mixture of air and solid creates the image of multiple artifacts in the anterior gastric wall, which typically blurs the posterior wall of the antrum. ${ }^{15,20}$ Due to the presence 
of air or gas bubbles an image with multiple points of echoes appears. After some time, the air moves from the stomach and the solid content can be better viewed as a mixture of echogenicity similar to "frosted glass." Peristaltic contractions are often observed in both the antrum and pylorus, particularly when there is content present. All images were obtained between peristaltic contractions.

Both qualitative and quantitative information of the gastric content were obtained. The qualitative assessment of the stomach was described initially, after identification of the gastric antrum. Four ultrasound images were considered, given that the examiner conducted the tests without knowing the nature of the ingested material. Therefore, the result described was based on the echogenicity of the image obtained. The examiner described the stomach in the following ways: 1 ) empty; 2) presence of liquid content when the image was hypoechoic; 3) solid content if hyperechoic and homogeneous, which corresponds to the ingestion of milk; and 4) gaseous image, due to the presence of hyperechoic points, which denotes the presence of gas and hence refers to the ingestion of solids (sandwich).

We used the measurement of the antral cross-sectional area (CSA) for a quantitative analysis, utilizing the technique described by Bolondi, ${ }^{22}$ and later by Perlas et al. ${ }^{14-16}$ evaluating the outer wall of the stomach. This was done in RLDP using two perpendicular diameters of the antrum, from serosa to serosa, the longitudinal or craniocaudal (CC) and the anteroposterior (AP) diameter, using the ellipse formula developed by Bolondi et al., ${ }^{22}$ where $\mathrm{CSA}=(\mathrm{CC} \times \mathrm{AP} \times \pi) / 4$. Where the value of $\pi=3.14$.

After calculating the CSA, the total volume of the stomach ("anticipated volume") was estimated in each volunteer using a mathematical model previously tested and validated by other authors ${ }^{23}$ where:

$$
\begin{gathered}
\text { Stomach volume }(\mathrm{mL})= \\
27+14.6 \times \mathrm{CSA}\left(\mathrm{cm}^{2}\right)-1.28 \times \text { age }(\text { in years })
\end{gathered}
$$

The ratio between the predicted volume and the weight of the volunteers was subsequently calculated by simple division.

To demonstrate the results a descriptive analysis of the demographic data (age, weight, height, and BMI), gender and ASA classification were used. The data were summarized using the mean and standard deviation.

The assessment of the different groups by the examiner was undertaken solely with the analysis and interpretation of the image in relation to the food ingested, with the result either right or wrong. The statistical anal- ysis was conducted using Chi-square $\left(\chi^{2}\right)$ test with a significance level of $5 \%$.

To compare the quantitative assessment of the gastric variables of the antral area, the predicted gastric volume and volume over the weight of the volunteers, we used the ANOVA test, with a significance level of 5\%.

\section{ResULTS}

Sixty-seven stomach ultrasound tests were performed on 30 volunteers. There were 19 fasting examinations and 16 examinations after the intake of each type of food: isotonic solution, milk and sandwich. Not all volunteers did the tests in the four situations. In all tests the stomach was located successfully. The data relating to the volunteers can be seen in Table 1 .

Fourteen of the 19 tests on fasting volunteers (73.68\%) were considered empty by the examiner. In this case, the antrum appears flat with the anterior and posterior walls juxtaposed. On the sagittal plane, it is round to oval and has been compared to a "target" or an image of a "bull's eye" (Figure 1A). On an axial plane, the empty antrum has the appearance of a "glove finger." $14,15,20,21,24$ The other four $(26.31 \%)$ volunteers presented images corresponding to the presence of liquid content in the stomach but with an estimated volume of less than $1.5 \mathrm{~mL} / \mathrm{kg}$.

The gastric content of the 16 volunteers who ingested isotonic solution was considered liquid in 13 (81.25\%) volunteers and solid in three $(18.72 \%)$ of them. With the presence of liquid in the stomach, the antrum appears with a distended rounded shape, fine walls and hypoechoic content (Figure 1B). Immediately after the intake of fluids, multiple gas bubbles may appear as hyperechoic points within the hypoechoic fluid, giving the appearance of a "starry night" of varying intensity. This appearance may lead to a different interpretation of the gastric content, as occurred in the three cases that were considered solid.

After the ingestion of $250 \mathrm{~mL}$ of milk, the examiner considered the gastric content as solid in 13 (81.25\%) volunteers, as liquid in two (12.50\%), and empty in one (6.25\%). With the intake of milk, the gastric antrum appears round and distended. Its contents, however, differ substantially from clear liquid, appearing with increased echogenicity (Figure 1C). Hypoechoic content with multiple hyperechoic points changed the interpretation in two cases, which were reported to be liquid content, and a case where the antrum appeared empty, with a gastric volume calculated as only $15 \mathrm{~mL}$.

After ingestion of solid content, the examiner found gaseous content in 15 (93.75\%) volunteers and solid content in one (6.25\%). The ingestion of solid food leads to the ap- 
pearance of an image that resembles "frosted glass" (Figure 1D). This is due to the mixture of air with food during the processes of chewing and swallowing. In some circumstances this may limit the view of some of the walls of the stomach, and make it difficult to assess the volume of the organ. The assessment of one case as solid was caused by an absence of air. The description of gaseous content for the ingestion of sandwiches was considered correct since the analysis was only undertaken on the image, ignoring the ingested material.

When analyzing the examiner's ability to discover the nature of the material present in the stomach there was no difference among the four groups ( $p>0.05$ ).

The result of the quantitative assessment of the gastric content, after eating different foods, can be seen in Table 1. There was a significant difference between the data obtained from the fasting volunteers and those who ingested isotonic drinks, milk or a sandwich $(\mathrm{p}<0.05)$. The gastric volumes were significantly greater with the intake of any of these substances and exceed the limit considered safe for the risk of gastric aspiration of $1.5 \mathrm{~mL} / \mathrm{kg}$ (Figure 2).

\section{Discussion}

The results show that the gastric antrum has a different appearance on ultrasound in the various situations studied, namely after fasting (while empty), after ingestion of clear liquid, milk and solid food. In addition, the gastric antrum expands from the baseline (empty state), with the entry of the volumes ingested, allowing it to be considered as "full," and thus differing from the empty state. Furthermore, based on the image of the antrum it was possible to calculate the cross-sectional area, allowing us to determine the total gastric volume, which proved to be compatible with the amount of food ingested.
One of the main complications faced by anesthesiologists in elective procedures and especially in emergencies, involving instrumentation of the upper airways, is pulmonary aspiration. In the United States, there are reports of an incidence of aspiration of 1:14,500 patients undergoing elective surgery, with a significant increase during tracheal intubation in emergency situations. ${ }^{24}$ The mortality rate is around 30 to $70 \%$, an event that is directly proportional to the volume, nature (liquid versus particulate or solid matter), and acidity of the aspirated material. ${ }^{8-10}$ Severe pulmonary aspiration requires ventilatory support in more than a third of patients, reaching a mortality rate of $5 \%$, representing more than $9 \%$ of all deaths related to anesthesia. ${ }^{23,25-27}$ Current strategies to prevent aspiration depend mainly on the recommended fasting periods. ${ }^{2,3}$ However, various medical conditions may predispose patients to present a high gastric content during anesthetic induction, regardless of the fasting time. ${ }^{5,28}$ This occurs, for example, in patients with slow gastric emptying such as patients with diabetes mellitus. ${ }^{29}$ On the other hand, patients who undergo emergency surgery often have significant gastric content, even if they are within the fasting time considered as being safe.

After the initial descriptions of gastric aspiration leading to severe pneumonias, a large number of studies have aimed to determine the minimum gastric volume responsible for pulmonary parenchymal lesions. Although there is no strict "threshold volume" above which there is an increased risk of aspiration, gastric fluid volumes up to 1.5 $\mathrm{mL} / \mathrm{kg}$ (around $100 \mathrm{~mL}$ for an average adult) are common in fasting patients and are considered safe. ${ }^{30-33}$ In our study, the ultrasound assessment of the gastric volume of volunteers with a fasting period of over 8 hours led the exam-

TABLE 1 Volunteer data and results of the USG assessment according to the group.

\begin{tabular}{lllll} 
& Fasting group & Isotonic group & Milk group & Sandwich group \\
\hline Age $($ years $)$ & $33.10 \pm 9.94$ & $30.50 \pm 8.21$ & $33.12 \pm 8.37$ & $31.56 \pm 8.51$ \\
\hline Weight $(\mathbf{k g})$ & $68.42 \pm 11.73$ & $68.18 \pm 12.00$ & $70.86 \pm 11.32$ & $70.16 \pm 11.68$ \\
\hline BMI $\left(\mathbf{k g} / \mathbf{m}^{2}\right)$ & $24.02 \pm 2.76$ & $23.88 \pm 2.66$ & $24.22 \pm 2.81$ & $24.39 \pm 3.55$ \\
\hline ASA & ASA 1: 16 & ASA 1: 14 & ASA 1: 11 & ASA 1: 15 \\
\cline { 2 - 5 } & ASA 2: 3 & ASA 2: 2 & ASA 2: 5 & ASA 2: 1 \\
\hline Gender & Male: 7 & Male: 6 & Male: 5 & Male: 5 \\
\cline { 2 - 5 } & Female: 12 & Female: 10 & Female: 11 & Female: 11 \\
\hline Area $\left(\mathbf{c m}^{2}\right)$ & $4.89 \pm 1.81^{*}$ & $15.28 \pm 5.32$ & $16.41 \pm 6.71$ & $10.89 \pm 3.62$ \\
\hline Volume $(\mathbf{m L})$ & $56.08 \pm 25.96^{*}$ & $211.19 \pm 78.26$ & $224.21 \pm 98.12$ & $145.62 \pm 56.02$ \\
\hline Volume $/ \mathbf{W e i g h t ~}(\mathbf{m L} / \mathbf{k g})$ & $0.82 \pm 0.37^{*}$ & $3.16 \pm 1.33$ & $3.28 \pm 1.81$ & $2.08 \pm 0.73$ \\
\hline
\end{tabular}

There was no difference in the demographic data of the volunteers in the four situations studied ( $p>0.05)$. There was a significant difference between the fasting group and the remaining regarding data obtained on USG $\left({ }^{*} p<0.05\right)$.

ASA: physical status classification according to the American Society of Anesthesiologists; BMI: body mass index; USG: ultrasonography. 
iner to consider the stomach as being empty in $73.68 \%$ of the reports, with the presence of liquid content observed in $26.3 \%$. This is certainly a result of normal gastric secretion because the volumes were below the limits considered at risk for aspiration (less than $1.5 \mathrm{~mL} / \mathrm{kg}$ ). Meanwhile, for the other groups that ingested isotonic solution, milk or a solid meal, the antrum was only considered empty in one case $(2 \%)$ and presented an estimated volume of $0.4 \mathrm{~mL} /$ $\mathrm{kg}$, although that was a volunteer who ingested milk. All of the others presented increased content within the stomach and thus were considered as a "full stomach." The presence of particulate matter was found in volunteers who ingested milk and solid meals.

In anesthesiology and emergency medicine, there is a great interest in assessing the state of gastric "fullness" at the bedside in order to assess the risk of pulmonary aspiration. Clinical decisions relating to the time of sur- gery and the choice of airway approach are based on the assumption that the patient has an "empty stomach" or "full stomach," according to the time elapsed since the last meal. However, the gastric emptying time varies significantly depending on pre-existing conditions, and fasting guidelines do not always guarantee an "empty stomach" in patients with gastric motility changes of any etiology. ${ }^{29}$ Furthermore, patients who undergo emergency surgeries normally have not fasted, or they may have a significant gastric content despite long periods without eating. Therefore, when the gastric "status" is unclear or unknown, an ultrasound examination performed at bedside can be very useful in assessing the risk of aspiration. In these cases, if the examination confirms the presence of a thick liquid or solid content, this is clearly a situation of high risk for aspiration, regardless of the exact volume. On the other hand, if the ultrasound
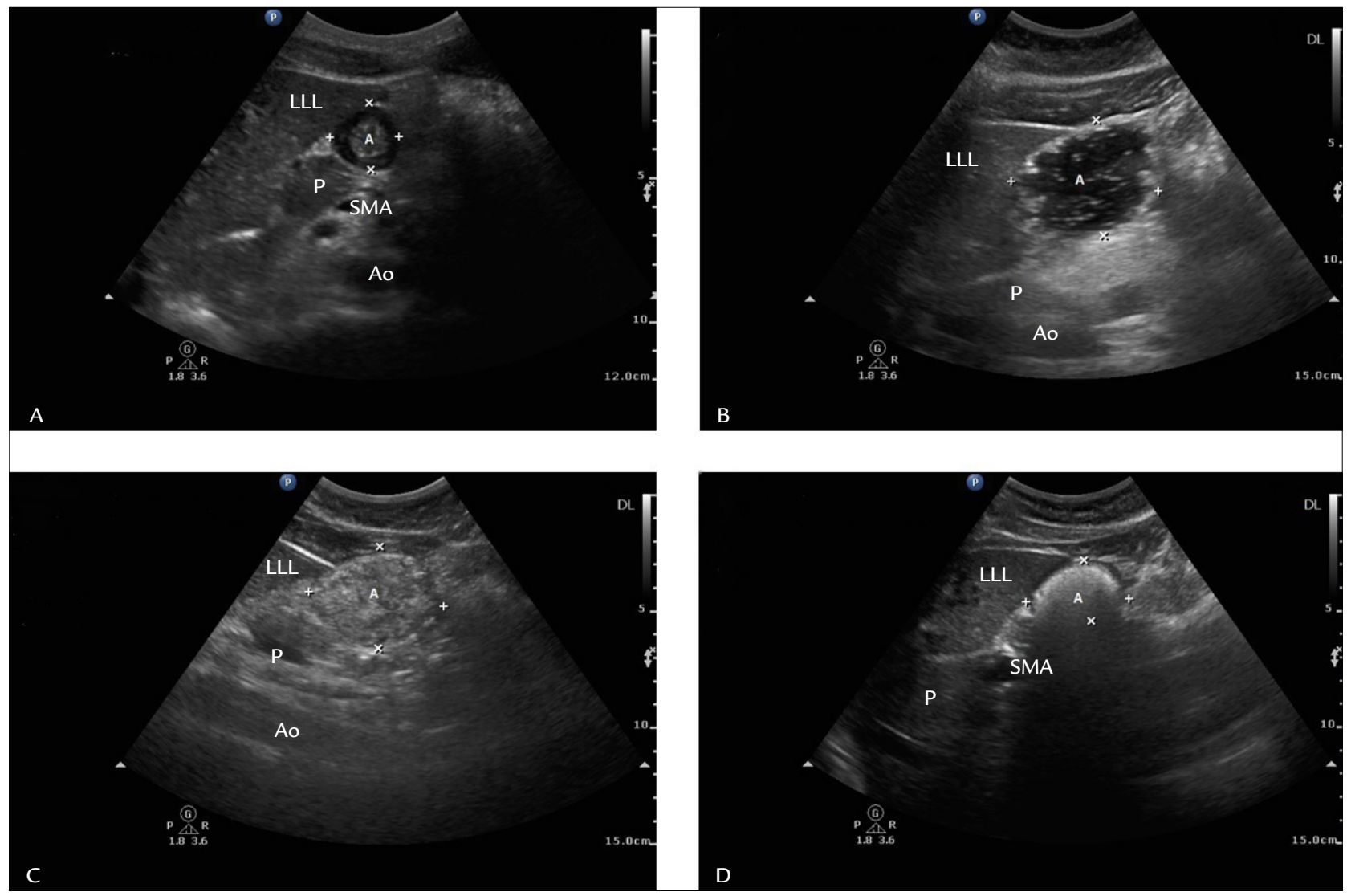

FIGURE 1 A. Ultrasonography image of the gastric antrum with an empty stomach. The antrum appears small and empty, with a "bull's eye" appearance. B. Ultrasonography image of the gastric antrum after ingestion of a clear fluid. Note that the antrum appears distended with hypoechoic or anechoic content. Small gas bubbles giving the appearance of a "starry night." C. Ultrasonography image of the gastric antrum after ingestion of milk. The antrum appears round and distended. There is increased echogenicity, with an image that resembles coagulated content. D. Ultrasonography image of the gastric antrum 10 minutes after ingestion of solid food (a sandwich). Image that resembles "frosted glass." A: gastric antrum; LLL: left lobe of the liver; P: pancreas; SMA: superior mesenteric artery; Ao: Aorta. 


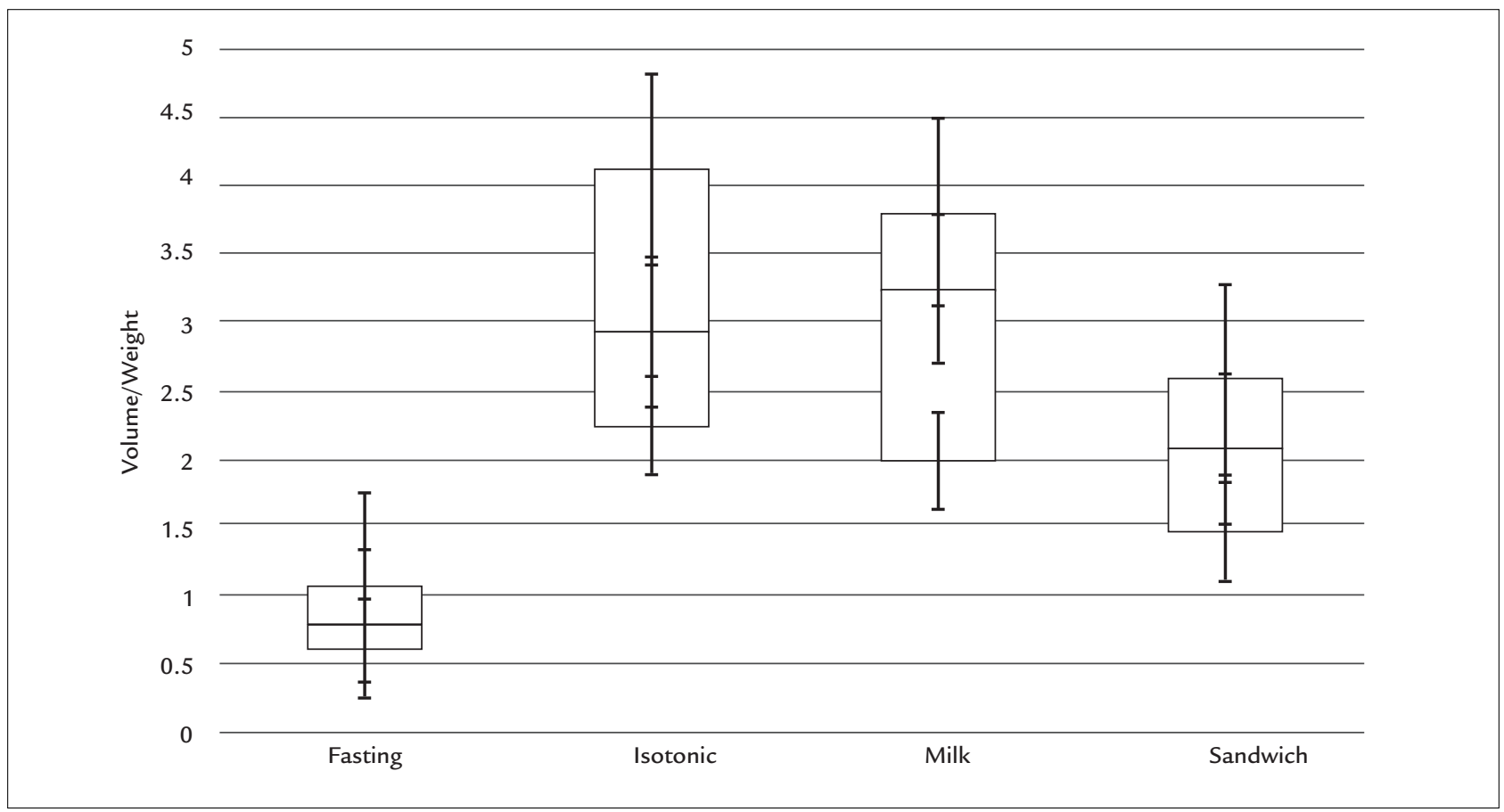

FIGURE 2 The volume/weight ratio was significantly lower in the fasting group compared to the three remaining groups $(p<0.05)$, which exceed the limit considered safe for risk for pulmonary aspiration of $1.5 \mathrm{~mL} / \mathrm{kg}$.

examination reveals an empty stomach, this is clearly a situation of low risk for aspiration. The presence of an empty stomach is a qualitative measurement, and does not require an assessment of the volume. However, if qualitative analysis identifies the presence of a liquid content, the quantitative assessment of the volume may help differentiate between a state of low volume (similar to the physiological baseline gastric content) and a state of greater volume and, therefore, greater risk..$^{15,21}$

In recent years the use of USG by anesthesiologists has been a perioperative resource that has improved several approaches, such as peripheral and spinal nerve locks, and facilitated venous and arterial punctures, cardiac procedures and many others. A growing body of evidence shows the benefits of the change in practice. ${ }^{34}$ The recent interest in the assessment of the stomach in order to evaluate the volume qualitatively and quantitatively before anesthesia plays a very important role in guiding decision-making. Determining the presence of an increased volume in the stomach helps to establish the risk of perioperative aspiration and thus serves as a guide in choosing the best preventive strategy. Up to now, the clinical applications of USG have been limited, although for more than two decades gastroenterologists have used this technique to access gastric motility and emptying ${ }^{35,36}$ and for the diagnosis of lesions of the stomach wall, such as cancer. ${ }^{37-39}$
Some authors have used USG to differentiate the nature of the gastric content. ${ }^{40}$ Bolondi $^{22}$ undertook the imaging of the gastric antrum in a transversal view and calculated its area. Based on this study, sequential measurements of the area of the antrum after the ingestion of standard meals were used to assess the gastric emptying time, with a good correlation with the scintigraphy. ${ }^{29,41,42}$ An observational study of 183 patients for elective or emergency surgery measured the gastric antrum area immediately before the induction of anesthesia. After tracheal intubation, a multi-hole $18 \mathrm{~F}$ probe was inserted into the stomach and its contents aspirated. There was a significantly positive correlation between the area of the antrum and the gastric volume aspirated. ${ }^{17}$

The USG technique is based on the insonation of several projections of the stomach, which facilitates the calculation of the transversal area of the gastric antrum and, as such, makes it possible to obtain different measurements that allow the correct assessment and characteristics of the gastric content. ${ }^{5}$ Several studies suggest that the gastric antrum is the region of the stomach that is the most amenable to ultrasound examination, ${ }^{14,18,20}$ and is identified in 98 to $100 \%$ of cases. ${ }^{15,17,21}$ By calculating the cross-sectional area of the antrum based on USG image, several mathematical models have been developed to determine the gastric volume. ${ }^{14-17}$ Furthermore, this 
method of assessing the gastric volume has proven to be reproducible and has little variability either when assessed by a single or multiple evaluators. ${ }^{43}$ The results were also shown to be equivalent with another assessment method that takes a dimensional measurement using the device's software, and this is not based on the assumption that the gastric antrum is a perfect ellipse..$^{14,22,36,43}$ The method can predict volumes of 0 to $500 \mathrm{~mL}$ and is applicable to adult patients with a BMI less than $40 \mathrm{~kg} / \mathrm{cm}^{2}$. It has sensitivity and specificity of $100 \%$, and is considered the gold standard for non-invasive assessment of the stomach. The margin of error in the measurements is only $\pm 6 \mathrm{~mL} .{ }^{16}$

It may currently be premature to anticipate how this new technology could affect the daily practice of anesthesiologists, although we believe it to be a promising clinical skill to be developed. More research needs to be conducted in relation to the sensitivity and specificity of the method, although it has been proven as a valid technique. ${ }^{16,17}$

There are several limitations in this study. First, it was conducted on healthy adult volunteers. As such, the results should not be extrapolated to other patient populations, such as children, the obese, or patients with specific diseases. Secondly, limited quantities of liquids and solid meals were ingested, meaning that larger volumes could render different images than the ones obtained. Finally, the tests were performed by a single examiner, a radiologist, using a high-definition device, making it difficult to extrapolate USG as a tool for use in anesthesiology at any time.

\section{Conclusion}

Our data suggest that USG can offer qualitative and quantitative information of the gastric content that can help in assessing the stomach for the risk for pulmonary aspiration.

\section{Conflict of interest}

The authors declare no conflict of interest.

\section{Resumo}

Avaliação qualitativa e quantitativa do conteúdo gástrico através da ultrassonografia

Objetivo: A aspiração pulmonar do conteúdo gástrico é uma das complicações mais temidas em anestesia. A sua prevenção depende do jejum pré-operatório e da identificação dos pacientes de risco. Não há um método diagnóstico que possa acessar o conteúdo gástrico a qualquer momento. O objetivo deste estudo realizado em volun- tários foi fazer uma avaliação qualitativa e quantitativa do conteúdo gástrico utilizando a ultrassonografia.

Método: O estudo foi realizado em 67 voluntários utilizando uma técnica já descrita de avaliação do antro gástrico, em quatro diferentes situações: jejum, após a ingestão de líquido claro, leite ou refeição sólida. Foi feita uma avaliação qualitativa e quantitativa do conteúdo gástrico por um radiologista que desconhecia o estado gástrico do voluntário. O antro foi considerado vazio, contendo líquido claro ou espesso, ou sólido. O volume total do estômago foi calculado com base na área seccional do antro. Um valor de $\mathrm{p}<0,05$ foi considerado estatisticamente significativo.

Resultados: Para cada tipo de conteúdo gástrico, as características ultrassonográficas do antro e de seu conteúdo foram descritas e ilustradas. A avaliação qualitativa pode distinguir um estômago vazio de outros com diferentes conteúdos. O volume gástrico calculado foi significativamente maior após a ingestão de qualquer alimento em comparação com o jejum.

Conclusão: A ultrassonografia à beira do leito pode determinar a natureza do conteúdo gástrico. Também foi possível diferenciar um antro vazio daquele com algum volume. Essas informações podem ser úteis na determinação do risco de aspiração gástrica, principalmente se a condição gástrica é desconhecida ou incerta.

Palavras-chave: conteúdo gástrico, área antral, aspiração pulmonar, jejum pré-operatório, ultrassonografia.

\section{References}

1. Mendelson CL. The aspiration of stomach contents into the lungs during obstetric anesthesia. Am J Obstet Gynecol. 1946; 52:191-205.

2. Practice guidelines for preoperative fasting and the use of pharmacologic agents to reduce the risk of pulmonary aspiration: application to healthy patients undergoing elective procedures - An updated report by the American Society of Anesthesiologists Committee on Standards and Practice Parameter Anesthesiology. 2011; 114:495-511.

3. Smith I, Kranke P, Murat I, Smith A, O’Sullivan G, Søreide E, et al Perioperative fasting in adults and children: guidelines from the European Society of Anaesthesiology. Eur J Anaesthesiol. 2011; 28(8):556-69.

4. Kinni ME, Stout MM. Aspiration pneumonitis: predisposing conditions and prevention. J Oral Maxillofac Surg. 1986; 44(5):378-84

5. Zaloga GP. Aspiration-related illnesses: definitions and diagnosis. JPEN J Parenter Enteral Nutr. 2002; 26(6 Suppl):S2-8.

6. Vanner RG, Pryle BJ, O’Dwyer JP, Reynolds F. Upper oesophageal sphincter pressure and the intravenous induction of anesthesia. Anaesthesia. 1992; 47(5):371-5.

7. Cotton BR, Smith G: The lower oesophageal sphincter and anaesthesia. Br J Anaesth. 1984; 56:37-46.

8. Raidoo DM, Roche DA, Brock-Utne JG, Marszalek A, Engelbrecht HE. Critical volume for pulmonary acid aspiration: reappraisal in a primate model. $\mathrm{Br}$ J Anaesth. 1990; 65(2):248-50.

9. James CF, Modell JH, Gibbs CP, Kuck EJ, Ruiz BC. Pulmonary aspiration effects of volume and $\mathrm{pH}$ in the rat. Anesth Analg. 1984; 63(7):665-8.

10. Engelhardt T, Webster NR. Pulmonary aspiration of gastric contents in anaesthesia. Br J Anaest. 1999; 83(3):453-60. 
11. Landreau B, Odin I, Nathan N. [Pulmonary aspiration: epidemiology and risk factors]. Ann Fr Anesth Reanim. 2009; 28(3):206-10.

12. Maughan RJ, Leiper JB. Methods for the assessment of gastric emptying in humans: an overview. Diabet Med. 1996; 13(5):S6-10.

13. Ju Won Seok. How to interpret gastric emptying scintigraphy. J Neurogastroenterol Motil. 2011; 17(2):189-91.

14. Perlas A, Davis L, Khan M, Mitsakakis N, Chan VW. Gastric sonography in the fasted surgical patient: a prospective descriptive study. Anesth Analg. 2011; 113(1):93-76

15. Perlas A, Chan VW, Lupu CM, Mitsakakis N, Hanbidge A. Ultrasound assessment of gastric content and volume. Anesthesiology. 2009; 111(1):82-9.

16. Perlas AM, Nicholas M, Lui L, Cino M, Haldipur N, Davis L, et al. Validation of a mathematical model of ultrasound-determined gastric volume by gastroscopic examination. Anesth Analg. 2013; 116(2):357-63.

17. Bouvet L, Mazoit JX, Chassard D, Allaouchiche B, Boselli E, Benhamou D. Clinical assessment of the ultrasonographic measurement of antral area for estimating preoperative gastric content and volume. Anesthesiology. 2011 114(5):1086-92.

18. Fujigaki T, Fukusaki M, Nakamura H, Shibata O, Sumikawa K. Quantitative evaluation of gastric contents using ultrasound. J Clin Anesth. 1993; 5(6):451-5.

19. Koenig SJ, Lakticova V, Mayo PH. Utility of ultrasonography for detection of gastric fluid during urgent endotracheal intubation. Intensive Care Med. 2011; 37(4):627-31.

20. Cubillos J, Tse C, Cham VWS, Perlas A. Bedside ultrasound assessment of gastric content: an observational study. Can J Anesth. 2012; 59(4):416-23.

21. Bouvet L, Miquel A, Chassard D, Boselli E, Allaouchiche B, Benhamou D. Could a single standardized ultrasonographic measurement of antral area be of interest for assessing gastric contents? A preliminary report. Eur J Anaesthesiol. 2009; 26(12):1015-9.

22. Bolondi L, Bortolotti M, Santi V, Calletti T, Gaiani S, Labò G. Measurement of gastric emptying time by real-time ultrasonography. Gastroenterology. 1985; 89(4):752-9.

23. Shime N, Ono A, Chihara E, Tanaka Y. Current status of pulmonary aspiration associated with general anesthesia: a nationwide survey in Japan. Masui. 2005; 54(10):1177-85.

24. Sakai T, Planinsic RM, Quinlan JJ, Handley LJ, Kim TY, Hilmi IA. The incidence and outcome of perioperative pulmonary aspiration in a university hospital: a 4-year retrospective analysis. Anesth Analg. 2006; 103(4):941-7.

25. Lienhart A, Auroy Y, Péquignot F, Benhamou D, Warszawski J, Bovet M, et al. Survey of anesthesia related mortality in France. Anesthesiology. 2006; 105(6):1087-97.

26. Lockey DJ, Coats T, Parr MJ. Aspiration in severe trauma: a prospective study Anaesthesia 1999; 54(11):1097-83

27. Warner MA, Warner ME, Weber JG. Clinical significance of pulmonary aspiration during the perioperative period. Anesthesiology. 1993; 78(1):56-62.
28. Kinni ME, Stout MM. Aspiration pneumonitis: predisposing conditions and prevention. J Oral Maxillofac Surg. 1986; 44(5):378-84.

29. Darwiche G, Björgell O, Thorsson O, Almér LO. Correlation between simultaneous scintigraphic and ultrasonographic measurement of gastric emptying in patients with type 1 diabetes mellitus. J Ultrasound Med. 2003; 22(5):459-66.

30. Read MS, Vaughan RS. Allowing pre-operative patients to drink: effects on patients' safety and comfort of unlimited oral water until 2 hours before anaesthesia. Acta Anaesthesiol Scand. 1991; 35(7):591-5.

31. Phillips S, Hutchinson S, Davidson T. Preoperative drinking does not affect gastric contents. Br J Anaesth. 1993; 70(1):6-9.

32. Harter RL, Kelly WB, Kramer MG, Perz CE, Dzwonczyk RR. A comparison of the volume and $\mathrm{pH}$ of gastric contents of obese and lean surgical patients. Anesth Analg. 1998; 86(1):147-52.

33. Hausel J, Nygren J, Lagerkranser M, Hellström PM, Hammarqvist F, Almström $\mathrm{C}$, et al. A carbohydrate-rich drink reduces preoperative discomfort in elective surgery patients. Anesth Analg. 2001; 93(5):1344-50.

34. Johnson DW, Oren-Grinberg A. Perioperative point-of-care ultrasonography: the past and the future are in anesthesiologists' hands. Anesthesiology. 2011; 115(3):460-2.

35. Søreide E, Hausken T, Søreide JA, Steen PA. Gastric emptying of a light hospital breakfast. A study using real time ultrasonography. Acta Anesthesiol Scand. 1996; 40(5):549-53

36. Darwiche G, Almér LO, Björgell O, Cederholm C, Nilsson P. Measurement of gastric emptying by standardized real-time ultrasonography in healthy subjects and diabetic patients. J Ultrasound Med.1999; 18(10):673-82.

37. Hata J, Haruma K, Manabe N, et al. Gastric cancer. In: Maconi G, Bianchi Porro G, editors. Ultrasound of the gastrointestinal tract medical radiology diagnostic imaging Series. Berlin: Springer-Verlag; 2007. Chapter 16.

38. Wong M, Shum S, Chau W, Cheng C. Carcinoma of stomach detected by routine transabdominal ultrasound. Biomed Imaging Interv J. 2010; 6(4):39-41.

39. Ishigami S, Yoshinaka H, Sakamoto F, Natsugoe S, Tokuda K, Nakajo A, et al. Preoperative assessment of the depth of early gastric cancer invasion by transabdominal ultrasound sonography (TUS): a comparison with endoscopic ultrasound sonography (EUS). Hepatogastroenterol. 2004; 51(58):1202-5.

40. Carp H, Jayaram A, Stoll M. Ultrasound examination of the stomach contents of parturients. Anesth Analg. 1992; 74(5):683-7.

41. Wong CA, Loffredi M, Ganchiff JN, Zhao J, Wang Z, Avram MJ. Gastric emptying of water in term pregnancy. Anesthesiology. 2002; 96(6):1395-400

42. Wong CA, McCarthy RJ, Fitzgerald PC, Raikoff K, Avram MJ. Gastric emptying of water in obese pregnant women at term. Anesth Analg. 2007; 105(3):751-5.

43. Kruisselbrink R, Arzola X, Endersby R, Tse C, Chan V, Perlas A. Intra- and interrater reliability of ultrasound assessment of gastric volume. Anesthesiology. $2014 ; 121(1): 46-51$ 